\title{
Reduction of faecal shedding of parasites in West African dwarf bucks fed yeast and Lactobacillus acidophilus
}

${ }^{1}$ Inyang, U. A. and ${ }^{2}$ Ososanya, T. O.

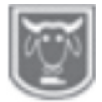

Abstract

Animal Production and Management Unit, ${ }^{1}$ Department of Animal Science, University of Uyo, Uyo ${ }^{2}$ Department of Animal Science, University of Ibadan, Ibadan Corresponding E-mail: udohinyang@yahoo.com

Ruminants serve as reservoirs of pathogenic microorganisms and their faecal shedding forms the vehicle of entry into human food chain which in turn causes food borne diseases. Usually drugs and live vaccines are the main control measures; however, due to increasing concerns of resistance and residues in meat with prophylactic drug use and the high cost of vaccines, alternative control methods are needed. The aim of this study was to determine if administration of probiotics could influence the shedding of faecal pathogenic bacteria and parasites/helminthes from WAD goats. In a completely randomised design, thirty goats were allotted to six dietary treatments which were formulated using concentrate as: control (D1); antibiotic (D2); $2.5 \mathrm{~g}$ bakers yeast (D3); $5.0 \mathrm{~g}$ bakers yeast (D4); $2.5 \mathrm{~g}$ yeast plus Lactobacilli (D5) and 5.0g yeast plus Lactobacilli (D6), where D5 and D6 were fortified with Lactobacillus acidophilus at $1.00 \times 10^{12} \mathrm{cfu} / \mathrm{g}$ each. Faecal samples (3g) were collected from bucks for faecal egg count reduction test (FECRT, \%). Data obtained were subjected to descriptive statistics and ANOVA $\alpha_{0.05}$. The results showed that the FECRT (\%) for the pathogenic bacteria revealed a significant $(p<0.05)$ reduction in load at two weeks by 99.99 $\%$ in D6 while the least was seen in D2 with $98.98 \%$. The salmonella as at day 14 recorded significant percentage reduction which was high in D5 (90\%) and lowest in D6 (19.23\%). The parasitic shedding of coccidia at day 14 showed that the goats on D1 shed 400 egg per gram (epg) while those on D3 recorded 150 epg. The animals on D2, D4, D5 and D6 recorded no trace of coccidia eggs in their faeces while animals on D5 and D6 showed reductions of 5.60 and $50.00 \%$ respectively in Ascaris. Tapeworm was identified only in faecal sample of D1. The result revealed that yeast combined with Lactobacillus acidophilus at $5 \mathrm{~g} /$ day could serve as a potential alternative to anti-bacteria and anti-helminthes.

Keywords: Bucks, Bakers yeast, Lactobacillus acidophilus, Pathogenic bacteria, Helminthes

\section{Introduction}

The presence of Escherichia coli, salmonella and helminthes on processed animal product is an indicator of faecal contamination (Murry et al., 2004). Antibiotics have been used extensively in animal feed to inhibit the growth of intestinal pathogens. However, the continued feeding of antibiotics at subtherapeutic levels has created concerns about the extent to which usage increases the possibilities of antibiotic residue, the development of drug-resistant bacteria, and a reduction in the ability to cure bacterial infections in humans (Jensen, 1998). Increased awareness of the potential problems associated with the use of antibiotics has stimulated research efforts to identify alternatives to their use as feed additives. Probiotics (direct-fed microbial) have been suggested as alternatives to the use of antibiotics in food animals.

Probiotics are live organisms with the capacity to benefit the gastrointestinal tract microflora by promoting health or preventing diseases in the host 


\section{West African dwarf bucks fed yeast and Lactobacillus acidophilus}

(Papadimitriou et al., 2007). Probiotics benefit the host by improving microbial balance, which includes the elimination or reduction of pathogenic microorganisms that are carried by the host and are harmful to humans (Zhao et al., 1998). The role of probiotics as microbial bioregulators is to maintain the balance of intestinal and ruminal microbiota, an important function to prevent intestinal adhesion and consequently the increase of the number of pathogenic bacteria such as Shiga toxinproducing Escherichia coli - STEC (Avila et al., 2000), salmonella and even helminthes. The levels of STEC shed in the faeces can be highly variable, and is influenced by a number of factors including age, season, and diet. Moreover, there are many differences in the shedding of $E$. coli in ruminants' guts, including individual variation and resident intestinal microbiota (Magnuson et al., 2000). Feeding probiotic bacteria to lambs decreased excretion of Escherichia coli O157:H7 (Lema et al., 2001 ), and direct-fed microbial supplementation also reduced Salmonella shedding in beef cattle (Stephens et al., 2007).

Hence, the objective of this study was to assess the efficacy of yeast alone and in combination with Lactobacillus acidophilus (probiotics) on reduction of faecal shedding of pathogenic bacteria and helminthes of WAD bucks (goats).

\section{Materials and methods \\ Experimental site}

The experiments were conducted at the University of Uyo Teaching and research farm, Uyo during raining period in July, and dry period in December of the same year.

\section{Feed additives used}

The yeast used was bakers' yeast named Angel procured from a supermarket. The mixed probiotic had yeast fortified with
Lactobacillus acidophilus at a concentration of $1.00 \times 10^{12} \mathrm{cfu} / \mathrm{g}$. Samoxine - an antibiotic with oxytetracycline hydrochloride as the active ingredient was used in this study. Probiotic was offered daily (g/day) that is the bakers yeast and mixed yeast plus Lactobacillus acidophilus.

Experimental diets, goats and management

The concentrate was mixed into six treatments as stated in Table 1. Concentrate was formulated and mixed with antibiotic, yeast (at $2.5 \mathrm{~g}$ and $5 \mathrm{~g}$ ) and mixed probiotic of yeast and LAB (Lactic Acid Bacteria) (at $2.5 \mathrm{~g}$ and $5 \mathrm{~g}$ ) on top plus Panicum maximum forage as follows:

Diet 1- Unsupplemented concentrate + Forage

Diet 2- Antibiotic supplemented concentrate + Forage

Diet 3- Supplemented concentrate (2.5 g yeast) + Forage

Diet 4- Suplemented concentrate (5 g yeast) + Forage

Diet 5- supplemented concentrate $(2.5 \mathrm{~g}-$ yeast + bacteria) + Forage

Diet 6- supplemented concentrate (5 g yeast + bacteria) + Forage

A total of thirty (30) bucks aged between one and two years and weighing $8.50 \pm 1.59$ $\mathrm{kg}$ on average were randomly allotted to six (6) treatments of five animals per treatment in a completely randomised design. Upon arrival at the experimental site, they were confined in groups after being balanced for weight for one month in order to stabilise them. Broad spectrum antibiotic (oxytetracycline LA) was administered at 1 $\mathrm{mL} / 10 \mathrm{~kg}$ body weight and Ivomec super (ivermectin) at $1 \mathrm{~mL} / 10 \mathrm{~kg}$ body weight through sub-cutaneous route. They were tagged for easy identification. The faecal samples were collected after this period for effect of probiotics on faecal pathogenic bacteria and parasites. Thereafter, they were 


\section{Inyang and Ososanya}

moved to individual pens measuring $2 \mathrm{~m} \mathrm{x}$ $1 \mathrm{~m}$ in concrete walled, floored but wood slatted upraised floor to hold the bucks. The pens were cleaned and washed thoroughly every two weeks with disinfectant to remove faecal droppings, dirts and odours. Feeding and drinking troughs were washed and disinfected.

Pathogenic bacteria and helminthes identification in faeces of bucks fed probiotic fortified diets

Eighteen (18) bucks used for the growth study of does were utilised for the faecal pathogenic and parasite identification study. Faecal samples were collected directly from the rectum of each buck on d $0,7$ and 14 . Three gram ( $3 \mathrm{~g})$ of faeces was homogenized by vigorous shaking in $10 \mathrm{ml}$ of sterile distilled water, larger particulate material was allowed to settle, and then 1 $\mathrm{ml}$ aliquots of faecal suspension were used as inocula for plates of MacConkey agar with incubation at $37^{\circ} \mathrm{C}$ for $24 \mathrm{~h}$ and enumerated as cfu/g. Salmonella was cultured on Salmonella shigella broth for 18 hours at $37^{\circ} \mathrm{C}$. Viable bacteria were counted after plating and incubated at $37^{\circ} \mathrm{C}$. The faecal egg count reduction test (\%) was calculated as:

FECRT $\%=[($ Initial EPG - Final $\mathrm{EPG} /$ /Initial EPG] $* 100 \%$

Where: FECRT is faecal egg count reduction test; EPG is egg per gram.

About $3 \mathrm{~g}$ of freshly collected faeces was weighed and mixed in $50 \mathrm{ml}$ of sterile distilled filtered water in a small beaker. The faecal lumps were broken using spatula, the solution was filtered through a tea strainer and the filtrate poured into test tubes of $20 \mathrm{~mL}$ capacity. The test tubes were placed in a centrifuge and spinned at $3000 \mathrm{rpm}$ for $15 \mathrm{mins}$. A drop of the supernatant was pipetted and fed into the Neubaer counter chamber. The counter was placed on a microscope stage and viewed. The total numbers of oocysts were calculated using the following formula:

(Chamber $1+$ Chamber 2) $\times 50=\mathrm{X}$ epg

Where epg = eggs per gram. Coccidia, ascaris and tapeworm population in the faecal samples were examined.

\section{Enumeration of intestinal pathogens}

After harvesting of the intestines, a 10 to 15 $\mathrm{cm}$ segment from three different portions of each of small and large intestines was cut and placed into a sterile tray. Each segment was further cut longitudinally, the contents removed and washed gently with sterile water. The mucus was collected by scraping gently with a glass slide. Distilled water was added to this mucus at a ratio of nine $\mathrm{ml}$ of water to one $\mathrm{ml}$ of mucus. It was then centrifuged at $3000 \mathrm{rpm}$ for 15 minutes. The resulting supernatant was serially diluted six-fold and plated on sterile petri dishes. The dishes contained Eosin methylene blue agar and Salmonella/Shigella agar. The plated dishes were then incubated at $37^{?} \mathrm{C}$ and $44.50{ }^{2} \mathrm{C}$ respectively for 24 hours to identify $E$. coli and salmonella colony forming unit (cfu) as described by Fuller et al. (1981).

\section{Statistical analysis}

The experimental design was completely randomized design (CRD). Data generated were subjected to the analysis of variance procedure of SAS (1999). Significant means were separated using the Duncan Multiple range test of the same software package. Experimental model of the design was: $\mathrm{Y}_{\mathrm{ij}}=$ $\mu+\alpha_{\mathrm{i}}+?_{\mathrm{ij}}$. Where Yij $=$ Individual observation; $\mu=$ general mean of population; $\alpha \mathrm{i}=$ treatment mean; $\Sigma \mathrm{ij}=$ composite error effect. 


\section{West African dwarf bucks fed yeast and Lactobacillus acidophilus}

Table 1: Gross composition (\%) of concentrate feed mixture

\begin{tabular}{ll}
\hline Ingredient (\%) & $\%$ \\
\hline Dried cassava peel & 45 \\
BDG & 40.70 \\
PKC & 10 \\
Limestone & 2.50 \\
Salt & 1.50 \\
Vitamin-mineral premix & 0.30 \\
Total & 100 \\
Calculated CP (\%) & 10.37 \\
Calculated ME MJ/Kg & 2.24 \\
\hline BDG - Brewers Spent Grains; PKC- Palm Kernel Cake; CP - Crude Protein; \\
ME - Metabolizable Energy
\end{tabular}

\section{Results}

\section{Pathogenic bacterial faecal shedding}

Table 2 shows the response of probiotic fortified diets on faecal shedding of pathogenic bacteria. Initial E. coli load showed that it ranged from 5.50 (D2) 70.50 (D5) $\times 10^{6} \mathrm{cfu} / \mathrm{g}$. There were significant $(p<0.05)$ reductions in the load after one week and at two weeks the load had reduced by $99.99 \%$ in animals on D6 while animals fed D2 recorded $98.98 \%$. The load ranged from 0.00 (D6) -0.06 (D1) $\mathrm{x} 10^{6} \mathrm{cfu} / \mathrm{g}$ as at day 14 . The animals fed probiotic fortified diets recorded a range of $0.00(\mathrm{D} 6)-0.05(\mathrm{D} 3) \times 10^{6} \mathrm{cfu} / \mathrm{g}$.

The Salmonella faecal population at initial day ranged from $26 \times 10^{4} \mathrm{cfu} / \mathrm{g}$ (D6) to 250 x $10^{4} \mathrm{cfu} / \mathrm{g}$ (D1). The bacteria (Salmonella) population showed significant $(\mathrm{p}<0.05)$ reduction at day 7 with a range of $0-160 x$ $10^{4} \mathrm{cfu} / \mathrm{g}$. As at day 7 the Salmonella was reduced by $100 \%$ in D4 and D5 (0.00 respectively) while that of D6 (8.00; reduction of $69.20 \%$ ) was higher than those of D1 and D2 (125 and 51; reduction of 50.00 and $57.50 \%$ respectively). However, at day 14 the reduction was still significant and within the range of 21 (D5) - 53 (D1) $\mathrm{x} 10^{4} \mathrm{cfu} / \mathrm{g}$. The percentage reduction was high in bucks on D5 (90\%) and lowest for those on D6 (19.23\%). The population seemed to decrease for bucks on D1, D2 and D3 from day 0 to day 14 (250 vs 53; 120 vs 41 and 245 vs $25 \times 10^{4} \mathrm{cfu} / \mathrm{g}$ respectively) but tended to increase for bucks on D4, D5 and D6 for day 7 - day 14 (0 vs 25; 0 vs 21 and 8 vs $\left.21 \times 10^{4} \mathrm{cfu} / \mathrm{g}\right)$.

Table 2: Effect of probiotic fortified diets on faecal shed pathogenic bacteria in WAD bucks

\begin{tabular}{|c|c|c|c|c|c|c|c|}
\hline Bacteria/Day & D1 & D2 & D3 & D4 & D5 & D6 & SEM \\
\hline \multicolumn{8}{|c|}{$E . \operatorname{coli}\left(\times 10^{6} \mathrm{cfu} / \mathrm{g}\right)$} \\
\hline E. coli $\mathrm{D} 0$ & $44.00^{\mathrm{b}}$ & $5.50^{\mathrm{d}}$ & $19.50^{\mathrm{cd}}$ & $31.33^{\mathrm{bc}}$ & $70.50^{\mathrm{a}}$ & $16.50^{\mathrm{cd}}$ & 5.64 \\
\hline E. coli D7 & $80.00^{\mathrm{a}}$ & $20.00^{\mathrm{d}}$ & $58.00^{\mathrm{b}}$ & $35.00^{\mathrm{c}}$ & $18.00^{\mathrm{d}}$ & $2.00^{\mathrm{e}}$ & 4.26 \\
\hline E. coli D14 & $0.06^{\mathrm{ab}}$ & $0.06^{\mathrm{ab}}$ & $0.05^{\mathrm{bc}}$ & $0.04^{\mathrm{c}}$ & $0.03^{\mathrm{d}}$ & $0.00^{\mathrm{e}}$ & 0.02 \\
\hline FECR \% & 99.86 & 98.98 & 99.74 & 99.86 & 99.95 & 99.99 & ND \\
\hline \multicolumn{8}{|c|}{ Salmonella (x 104 cfu/g) } \\
\hline Salmonella D0 & $250.00^{\mathrm{a}}$ & $120.00^{\mathrm{c}}$ & $245.00^{\mathrm{a}}$ & $85.00^{\mathrm{d}}$ & $210.00^{\mathrm{b}}$ & $26.00^{\mathrm{e}}$ & 5.53 \\
\hline Salmonella D7 & $125.00^{\mathrm{b}}$ & $51.00^{c}$ & $160.00^{\mathrm{a}}$ & $0.00^{\mathrm{d}}$ & $0.00^{\mathrm{d}}$ & $8.00^{\mathrm{d}}$ & 5.53 \\
\hline Salmonella D14 & $53.00^{\mathrm{a}}$ & $41.00^{\mathrm{b}}$ & $25.00^{c}$ & $25.00^{c}$ & $21.00^{c}$ & $21.00^{c}$ & 1.56 \\
\hline FECR \% & 78.80 & 65.83 & 89.80 & 70.59 & 90.00 & 19.23 & ND \\
\hline
\end{tabular}




\section{Inyang and Ososanya}

\section{Parasitic/helminthes faecal shedding}

The faecal parasitic shedding of WAD goats fed probiotic fortified diets are presented in Table 3 . The coccidia were initially (day 0 ) not identified in faeces of the bucks except for those on D3, D5 and D6 (50, 50 and 250 epg respectively). At day 7 , buck on D6 (400 from $250 \mathrm{epg}$ ) recorded the highest while those on D1, D3, D4 and D5 had the least (0 epg). However, at day 14 bucks on D1 shed 400 epg while those on D3 recorded 150 epg. The bucks on D2, D4, D5 and D6 recorded no trace of coccidia eggs in their faeces and these were significantly $(p<0.05)$ lower than those of D1 and D3.

The ascaris load was highest $(p<0.05)$ in faeces of bucks on D1 (1350 epg) and lowest in those of D2 (350 epg). There were reductions in ascaris load in the bucks on
D1, D5 and D6 (400, 550 and 500 epg) but those on D2, D3 and D4 (850, 700 and 600 epg) recorded increases at day 7 . When compared with the initial day, bucks on D1 returned to the initial load (1350 epg) which was significantly $(\mathrm{p}<0.05)$ different from other treatments. Similarly, those on D3 returned to 300 epg but this was after it had gotten to 700 epg at day 7 . There were decreases in faecal population of ascaris (day 14 compared with day 0) except for D2 and D4, whose FECR \% was 42.90 and $10.00 \%$ respectively. Goats on D5 and D6 showed reductions of 5.60 and $50.00 \%$ respectively.

Tapeworm was only identified in faecal samples of goats on D2 from day 7 to day 14 (50 respectively), while the other goats had no trace of the worm.

Table 3: Parasitic shedding (epg) in faeces of WAD goats fed probiotic fortified diets

\begin{tabular}{llllllll}
\hline Parasite/Day & D1 & D2 & D3 & D4 & D5 & D6 & SEM \\
\hline Cocc. D0 & $0^{\mathrm{b}}$ & $0^{\mathrm{b}}$ & $50^{\mathrm{b}}$ & $0^{\mathrm{b}}$ & $50^{\mathrm{b}}$ & $250^{\mathrm{a}}$ & 20.41 \\
Cocc. D7 & $0^{\mathrm{c}}$ & $200^{\mathrm{b}}$ & $0^{\mathrm{c}}$ & $0^{\mathrm{c}}$ & $0^{\mathrm{c}}$ & $400^{\mathrm{a}}$ & 26.35 \\
Cocc. D14 & $400^{\mathrm{a}}$ & $0^{\mathrm{c}}$ & $150^{\mathrm{b}}$ & $0^{\mathrm{c}}$ & $0^{\mathrm{c}}$ & $0^{\mathrm{c}}$ & 26.35 \\
FECR \% & +400 & -100 & +200 & - & -100 & -100 & ND \\
Ascaris D0 & $1350^{\mathrm{a}}$ & $350^{\mathrm{d}}$ & $400^{\mathrm{d}}$ & $500^{\mathrm{d}}$ & $900^{\mathrm{b}}$ & $700^{\mathrm{c}}$ & 60.38 \\
Ascaris D7 & $400^{\mathrm{b}}$ & $850^{\mathrm{a}}$ & $700^{\mathrm{ab}}$ & $600^{\mathrm{ab}}$ & $550^{\mathrm{ab}}$ & $500^{\mathrm{b}}$ & 98.60 \\
Ascaris D14 & $1350^{\mathrm{a}}$ & $500^{\mathrm{c}}$ & $400^{\mathrm{c}}$ & $550^{\mathrm{c}}$ & $850^{\mathrm{b}}$ & $350^{\mathrm{c}}$ & 66.66 \\
FECR \% & - & +42.90 & - & +10.00 & -5.60 & -50.00 & ND \\
Tapeworm D0 & 0 & 0 & 0 & 0 & 0 & 0 & 0 \\
Tapeworm D7 & $0^{\mathrm{b}}$ & $50^{\mathrm{a}}$ & $0^{\mathrm{b}}$ & $0^{\mathrm{b}}$ & $0^{\mathrm{b}}$ & $0^{\mathrm{b}}$ & 11.78 \\
Tapeworm D14 & $0^{\mathrm{b}}$ & $50^{\mathrm{a}}$ & $0^{\mathrm{b}}$ & $0^{\mathrm{b}}$ & $0^{\mathrm{b}}$ & $0^{\mathrm{b}}$ & 11.78 \\
FECR \% & - & +50 & - & - & - & - & ND \\
\hline a.b,c,c,de $=$ - & - & - & - & - &
\end{tabular}

$\mathrm{a}, \mathrm{b}, \mathrm{c}, \mathrm{d}, \mathrm{e}=$ means on the same row bearing different superscripts differ $(\mathrm{p}<0.05)$ significantly

D1: -ve Control; D2: +ve Control (Antibiotic); D3: Yeast 2.5g/d; D4: Yeast 5.0g/d; D5: LAB+Yeast 2.5g/d and D6: LAB+Yeast 5.0g/d;

LAB: Lactobacillus acidophilus; epg: egg per gramme; ND - Not determined; Cocc-Coccidia; FECR \%: Faecal Egg Count Reduction

\section{Intestinal bacterial pathogens population}

Table 4 shows the population of two pathogenic bacteria isolated from the intestines (small and large) of bucks fed probiotic fortified diets. The population of $E$. coli within the small intestine was significantly $(\mathrm{p}<0.05)$ different amongst the treatments. The bucks fed probiotic fortified diets (D3 - D6) together with those on D2 were similar $(p>0.05)$, recording no presence of $E$. coli but were different $(\mathrm{p}<0.05)$ from the control (D1) which had $24 \times 10^{6} \mathrm{cfu} / \mathrm{g}$. Within the large intestine, the presence of $E$. coli was found in the controls (D1 and D2 - 51.67 and 0.67 $\mathrm{x} 10^{6} \mathrm{cfu} / \mathrm{g}$ respectively), which were different $(p<0.05)$ from each other, while none was present in the goats fed probiotics fortified diets. 


\section{West African dwarf bucks fed yeast and Lactobacillus acidophilus}

Table 4: Population $\left(\times 10^{6} \mathrm{cfu} / \mathrm{g}\right)$ of pathogenic organisms in intestines of bucks

\begin{tabular}{|c|c|c|c|c|c|c|c|}
\hline Organisms & D1 & D2 & D3 & D4 & D5 & D6 & SEM \\
\hline E. coli SI & $24.00^{\mathrm{a}}$ & $0.00^{\mathrm{b}}$ & $0.00^{\mathrm{b}}$ & $0.00^{\mathrm{b}}$ & $0.00^{\mathrm{b}}$ & $0.00^{\mathrm{b}}$ & 1.25 \\
\hline E. coli $\mathrm{LI}$ & $51.67^{\mathrm{a}}$ & $0.67^{b}$ & $0.00^{\mathrm{b}}$ & $0.00^{\mathrm{b}}$ & $0.00^{\mathrm{b}}$ & $0.00^{\mathrm{b}}$ & 1.81 \\
\hline Salmonella SI & $13.33^{b}$ & $0.00^{\mathrm{c}}$ & $45.00^{\mathrm{a}}$ & $38.00^{\mathrm{a}}$ & $10.00^{\mathrm{bc}}$ & $15.00^{\mathrm{b}}$ & 3.48 \\
\hline Salmonella LI & $15.33^{b}$ & $0.00^{\mathrm{c}}$ & $30.00^{\mathrm{a}}$ & $26.67^{\mathrm{ab}}$ & $36.67^{\mathrm{a}}$ & $38.33^{\mathrm{a}}$ & 3.73 \\
\hline
\end{tabular}

Salmonella population was affected $(\mathrm{p}<$ $0.05)$ by the treatments in the small intestine. Highest $(p<0.05)$ number was found in goats fed with the probiotic fortified diets, ranged from 10 (D5) -45 (D3) $\times 10^{6} \mathrm{cfu} / \mathrm{g}$, when compared with the controls except D5 which was similar ( $p>$ 0.05 ) with the controls (D1 and D2 - 13.33 and $\left.0.00 \times 10^{6} \mathrm{cfu} / \mathrm{g}\right)$. However, bucks on D2 showed no presence of Salmonella in the small intestine. In the large intestine, no presence of Salmonella was detected for D2 just as in the small intestine. Goats placed on probiotic fortified diets recorded a higher $(\mathrm{p}<0.05)$ number of Salmonella, ranging from 26.67 (D4) to 38.33 (D6) $\times 10^{6}$ $\mathrm{cfu} / \mathrm{g}$, except for D4 $\left(26.67 \times 10^{6} \mathrm{cfu} / \mathrm{g}\right)$ which was similar $(\mathrm{p}>0.05)$ with $\mathrm{D} 1$ $\left(15.33 \times 10^{6} \mathrm{cfu} / \mathrm{g}\right)$.

\section{Discussion}

\section{Pathogenic bacterial faecal shedding}

Various researchers have reported that lactobacillus strains, such as Lactobacillus spp., Bifidobacteria spp., Enterococcus spp., Lactococcus spp., Streptococcus spp., etc. may possess immune enhancing activities or are able to produce bacteriocins to protect the host from infection by pathogens (Simova et al., 2009). The possible mechanisms by which probiotics may offer protection against infection by gastrointestinal pathogens have been addressed in diverse patent applications. This include: modification of the intestinal environmental; competition with pathogens for nutrients and colonization of adhesion sites in the intestinal environment; competition with pathogens for nutrients and sites on intestinal epithelium; production of antimicrobial metabolites; and modulation of immune and non-immune defence mechanisms of the host (Timmerman et al., 2004). Our results suggest the occurrence of the protective effect from probiotics strains against the shedding of E. coli and Salmonella, since a lower number/count of both pathogenic bacteria was recovered from the probiotic fortified groups compared to control groups. This assertion is in agreement with the reports of various authors in lambs (Mwenya et al., 2004), cattle (Brashears et al., 2003; Stephens et al. 2007).

\section{Parasitic/helminthes faecal shedding}

The reduction in the sporulation of the oocysts observed in this study supports the hypothesis that lactic acid bacteria produces antimicrobial compound that is harmful not only to coccidia oocysts as stated by Tierney et al. (2004) but also ascarids and tapeworm. Many studies reported the inhibition of a wide range of pathogenic microorganisms by lactic acid bacteria under in vitro and in vivo conditions, such as Escherichia coli, Salmonella, and rotavirus (Rolfe, 2000; Belfiore et al., 2007). Mice fed Lactobacillus acidophilus (LA) or Lactobacillus reuteri (LR) and experimentally infected with bovine Cryptosporidium parvum shed lower numbers of oocysts and had a shortened duration of shedding compared to non- 